\title{
Tadalafil alters energy metabolism in C2C12 skeletal muscle cells ${ }^{\star}$
}

\author{
Stefania Sabatini ${ }^{1}$, Paolo Sgrò${ }^{2}$, Guglielmo Duranti ${ }^{1}$, Roberta Ceci ${ }^{1 凶}$ and Luigi Di Luigi² \\ Unit of Biochemistry and Molecular Biology, 2Unit of Endocrinology; Department of Health Sciences, University of Rome "Foro Italico", \\ Rome, Italy
}

\begin{abstract}
Phosphodiesterases (PDEs) are a family of enzymes that hydrolyze cyclic nucleotides, thereby modulating cell functions. Three highly selective PDE5 inhibitors (PDE5i), sildenafil, vardenafil and tadalafil, have been developed for treatment of erectile dysfunction (ED). Experimental evidence showed that chronic treatment with sildenafil PDE5 $i$ in a mouse model of diet-induced obesity and insulin resistance improved insulin action and decreased circulating fatty acid levels. It has recently been shown that healthy athletes use PDE5i as performance enhancers, hence in the present study we investigated whether the long-lasting PDE5i tadalafil influences energy metabolism in C2C12 skeletal muscle cells by evaluating lactate production, glucose consumption, and citrate synthase and $3-\mathrm{OH}$ acyl $\mathrm{CoA}$ dehydrogenase activities. Our data demonstrate that tadalafil is able to modulate energy homeostasis in mouse skeletal muscle cells, depending on the treatment length and dose.
\end{abstract}

Keywords: phosphodiesterase type 5 inhibitor, lactate, aerobic enzymes

Received: 21 January, 2011; revised: 12 May, 2011; accepted: 14 June, 2011; available on-line: 16 June, 2011

\section{INTRODUCTION}

The cyclic nucleotides cAMP and cGMP are important second messengers that play key regulatory roles in a variety of signal transduction pathways and tissues (Soderling \& Beavo, 2000). Alterations in their intracellular concentration influence cell function. For example, they can mediate processes such as platelet aggregation (Dickinson et al., 1997), T cell activation (Li et al., 1999) and smooth cell relaxation (Omori \& Kotera, 2007). Phosphodiesterases (PDEs) are a family of enzymes with differing selectivity for cyclic nucleotides, sensitivity to inhibitors and activators, physiological roles and tissue distributions. PDEs hydrolyze cyclic nucleotides, thereby modulating their intracellular levels and hence affecting cell function (Omori \& Kotera, 2007). Three highly selective PDE5 inhibitors, sildenafil, vardenafil and tadalafil, which are comparable in their inhibition activity but differ in pharmacokinetic properties, have been developed for the treatment of erectile dysfunction (ED) (Corbin \& Francis, 2002). In addition to their effects on ED, chronic administration of PDE5i has been approved as a therapeutic tool for pulmonary arterial hypertension (Vachiery et al., 2011). Moreover, several studies evaluated the use of PDE5i for the treatment of other pathological conditions (benign prostatic hyperplasia, myocardial ischemia) (Salloum et al., 2009; Liu et al., 2011).

Anecdotal evidence has reported a worldwide misuse of PDE5i in healthy athletes as performance enhancers and in air force pilots to counteract the effects of high altitude. Experimental studies have been performed in vivo to evaluate whether sildenafil and tadalafil may influence exercise performance. One study indicated that a single dose of tadalafil did not influence anaerobic performance indices (Di Luigi et al., 2008). In contrast, another study that examined anaerobic performance indices using the 30-s Wingate test showed that tadalafil significantly increased the blood lactate value at the $3 \mathrm{~min}$ point of the recovery phase (Guidetti et al., 2008).

Sildenafil was able to improve insulin action, and chronic exposure induced a statistically significant reduction in body mass and a decrease in circulating fatty acids in a mouse model of diet-induced obesity and insulin resistance (Ayala et al., 2007).

Our aim was to investigate the effects of phosphodiesterase inhibition in skeletal muscle, which is quantitatively the most important insulin-sensitive and metabolically active tissue and therefore may represent a major target for PDE5i action.

To this end, we evaluated the influence of tadalafil on energy metabolism in the mouse $\mathrm{C} 2 \mathrm{C} 12$ cell line, a wellknown model for in vitro skeletal muscle studies.

\section{MATERIALS AND METHODS}

Tadalafil solution. We purified tadalafil from Cialis (C) $20 \mathrm{mg}$ tablets according to the method of Flores et al. (2004). Briefly, one tablet (corresponding to $20 \mathrm{mg}$ of compound) was pulverized and dissolved in $90 \mathrm{ml}$ of methanol. This solution was sonicated for 10 minutes and centrifuged at $14000 \times \mathrm{g}$ for 10 minutes at $+4{ }^{\circ} \mathrm{C}$. The supernatant was then transferred to tubes and tested for tadalafil purity by comparing its absorbance spectra with that published by Cheng and Chou (2005).

Cell culture. C2C12 myoblasts $\left(2 \times 10^{3} / \mathrm{cm}^{2}\right.$; ATCC, Manassas, VA, USA) were cultured in $25 \mathrm{~cm}^{2}$ cul-

\footnotetext{
\ e-mail: roberta.ceci@uniroma4.it

*The results of this paper were presented as a poster at the XXXIV Congresso della Società Italiana di Endocrinologia and XXVII Giornate Endocrinologiche Pisane held in Pisa simultaneously in June 2010. J Endocrinol Invest 33 (Suppl 4): P008.

Abbreviations: CS, citrate synthase; DMEM, Dulbecco's-modified Eagle's medium; ED, erectile dysfunction; FBS, foetal bovine serum; $H A D, 3-O H$ acylCoA dehydrogenase; RT-PCR, reverse transcription polymerase chain reaction; PDE5, phosphodiesterase type 5; PDE5i, phosphodiesterase type 5 inhibitor
} 
ture flasks with Dulbecco's-modified Eagle's medium (DMEM; HyClone, Oud-Beijerland, Holland) supplemented with Glutamax-I (4 mM L-alanyl-L-glutamine), $4.5 \mathrm{~g} / 1$ glucose (Invitrogen, Carlsbad, CA, USA) and $10 \%$ heat-inactivated fetal bovine serum (FBS; HyClone). No antibiotics were used. The cells were incubated at $37^{\circ} \mathrm{C}$ with $5 \% \mathrm{CO}_{2}$ in a humidified atmosphere. Cells were split 1:6 twice weekly and fed $24 \mathrm{~h}$ before each experiment.

Differentiation into myotubes was achieved by culturing preconfluent cells ( $85 \%$ confluency) in medium containing $2 \%$ FBS and monitoring them by microscopy and for myogenin expression. Myogenin expression was evaluated by western blot analysis as previously described (Catani et al., 2004).

Tadalafil was dissolved in methanol at a stock concentration of $300 \mu \mathrm{M}$ immediately before use and then diluted in the culture medium to a final concentration of 0.5 or $1 \mu \mathrm{M}$. At these concentrations of working solution, the methanol concentration $(0.1 \%, \mathrm{v} / \mathrm{v})$ does not have any specific effect on the muscle cells.

Reverse transcriptase polymerase chain reaction (RT-PCR). Total RNA was extracted using the RNeasy Mini kit (Qiagen GmbH, Hilden, Germany) according to the manufacturer's instructions, and residual DNA was removed by on-column DNAse digestion using the RNase-Free DNAse set (Qiagen). The extracted RNA was used for reverse transcription polymerase chain reaction (RT-PCR). Briefly, $1.0 \mu \mathrm{g}$ of RNA was reversetranscribed for $1 \mathrm{~h}$ at $42{ }^{\circ} \mathrm{C}$ with SuperScript II reverse transcriptase (Invitrogen) in the presence of $25 \mathrm{ng} / \mathrm{ml}$ Oligo(dT) $)_{12-18}, 500 \mu \mathrm{M}$ dNTPs and $200 \mathrm{U}$ RNase inhibitor (Promega, Madison, WI, USA) in a $20 \mu \mathrm{l}$ final volume. Subsequently, $2 \mu \mathrm{l}$ of cDNA was amplified using 2.5 $\mathrm{U}$ of Platinum Taq (Invitrogen) in the presence of 15 pmol of specific primers as follows:

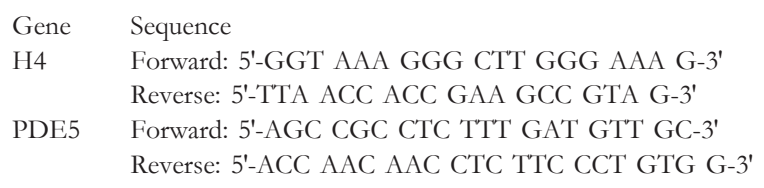

In all experiments, cDNA was initially denatured for 3 min at $94^{\circ} \mathrm{C}$, followed by step-cycle amplification consisting of $30 \mathrm{~s}$ denaturation $\left(94^{\circ} \mathrm{C}\right), 25 \mathrm{~s}$ annealing $\left(57^{\circ} \mathrm{C}\right)$ and $20 \mathrm{~s}$ extension $\left(72^{\circ} \mathrm{C}\right)$ using a Biorad iCycler thermal cycler (Bio-Rad Laboratories, Inc. Hercules, CA, USA). The exponential amplification range was 22-37 cycles for histone 4 (H4) used as a positive control for RT-PCR (not shown) and 28-43 cycles for PDE5. Quantification of PCR-amplified products was performed using a FluorS imager (Bio-Rad Laboratories) and ImageQuant software to quantify the ethidium bromide signal.

cGMP assay. cGMP from cell lysates was measured by immunoenzymatic assay using a commercial kit (RD System Inc., Minneapolis, USA). Briefly, cells were washed in cold PBS, resuspended in cell lysis buffer and then frozen and thawed in repeated cycles until cells were completely lysed. Samples were then centrifuged to remove cellular debris, and the collected supernatant was used for the immunoenzymatic assay. The sensitivity of the method was $0.56 \mathrm{pmol} / \mathrm{ml}$. The intra- and interassay coefficients of variation were $3.9 \%$ and $7.7 \%$, respectively.

Glucose consumption. The cell culture media glucose level was determined spectrophotometrically by a manual procedure using a commercial test kit (Greiner
Diagnostic GmbH, Bahlingen-Germany). Ten microliters of medium was incubated in hexokiase glucose6-phosphate dehydrogenase buffer for 5 minutes, and the resulting NADH production was determined at $340 \mathrm{~nm}$. Glucose amounts are presented as means \pm S.D. of three independent experiments, each performed in triplicate and represented as the increase relative to control cells.

Lactate production. Cell culture media lactate was determined spectrophotometrically using a commercial test kit (Greiner Diagnostic). Twenty microliters of medium was incubated in lactate oxidase buffer for 5 minutes. NADH production was determined at $340 \mathrm{~nm}$. Lactate amounts are presented as means \pm S.D. of three independent experiments, each performed in triplicate and represented as the increase relative to control cells.

Enzymatic activities. After each treatment, cells were trypsinized and centrifuged at $1200 \times g$ for 10 minutes at room temperature. Cells were then lysed with an extraction buffer $(0.05 \mathrm{M}$ Tris/acetate, 250 $\mathrm{mM}$ sucrose, $\mathrm{pH}$ 7.5) containing $1 \mathrm{mM}$ phenylmethylsulfonyl fluoride (PMSF) and protease inhibitor cocktail (P8340, Sigma-Aldrich, St. Louis, MO, USA). After gentle sonication (twice for $10 \mathrm{~s}$ on ice) with Vibra-Cell CV 18 SONICS VX 11 (Sonics \& Materials, CT, USA) and centrifugation at $14000 \times g$ for $10 \mathrm{~min}$ at $+4{ }^{\circ} \mathrm{C}$, the supernatants were tested for protein content using the Bradford method (Sigma-Aldrich) and then analyzed spectrophotometrically (Perkin Elmer Lambda 25, Fremont, CA, USA) for different enzymatic activities (Mounier et al., 2007).

Citrate synthase (CS). CS activity measurements were determined using Ellman's reagent [5,5'-dithiobis-(2-nitrobenzoic acid) (DTNB)] in an assay mixture containing $1 \mathrm{mM}$ DTNB in Tris/ $\mathrm{HCl} 1 \mathrm{M}, \mathrm{pH}$ 8.0, 10 $\mathrm{mM}$ Acetyl-CoA, $10 \mathrm{mM}$ oxaloacetate and $50 \mu \mathrm{l}$ sample (Srere, 1969). The linear increase in absorbance was measured at $412 \mathrm{~nm}$. Data are expressed as mean \pm S.D. of $\mathrm{mU}$ enzyme/mg protein of three independent experiments, each performed in triplicate.

3-hydroxy acylCoA dehydrogenase (HAD). HAD activity measurements were undertaken by absorbance measurement at $340 \mathrm{~nm}$, which represented the oxidation of $\mathrm{NADH}$ at $30^{\circ} \mathrm{C}$ in an assay mixture containing $50 \mathrm{mM}$ triethanolamine/ $\mathrm{HCl}(\mathrm{pH}$ 7.0), 4 mM EDTA, $0.04 \mathrm{mM}$ NADH, $0.015 \mathrm{mM}$ S-acetoacetyl-CoA and $50 \mu \mathrm{l}$ sample (minimum $100 \mu \mathrm{g}$ protein) (Essen-Gustavsson \& Henriksson, 1984). Data are expressed as mean \pm S.D. of $\mathrm{mU}$ enzyme/mg protein of three independent experiments, each performed in triplicate.

One unit of enzymatic activity was defined as the amount of enzyme that forms $1.0 \mu \mathrm{mol}$ of product per minute.

All chemical reagents, unless otherwise specified, were purchased from Sigma-Aldrich Chemical (St. Louis, MO, USA).

Statistical analysis. The Kolmogorov-Smirnov test was used to evaluate the variable distribution, and all data are expressed as mean values \pm S.D. when normally distributed. A one-way ANOVA for repeated measures and specific post-hoc analyses were used to determine significant variations over time and among groups for each parameter evaluated. $P<0.05$ was accepted as significant. The SPSS statistical package (Version 17.0 for Windows; SPSS Inc., Chicago, IL, USA) was used for statistical analysis. 


\section{RESULTS AND DISCUSSION}

Phosphodiesterase 5 enzymes are the specific target of the long-acting inhibitor tadalafil (Kulkarni \& Patil, 2004). Although PDE5s are present in skeletal muscle (Loughney et al., 1998), no previous studies have reported their presence in $\mathrm{C} 2 \mathrm{C} 12$ cells.

We performed a semiquantitative RT-PCR that demonstrated that PDE5 mRNA was expressed in proliferating and differentiated cells (Fig. 1).

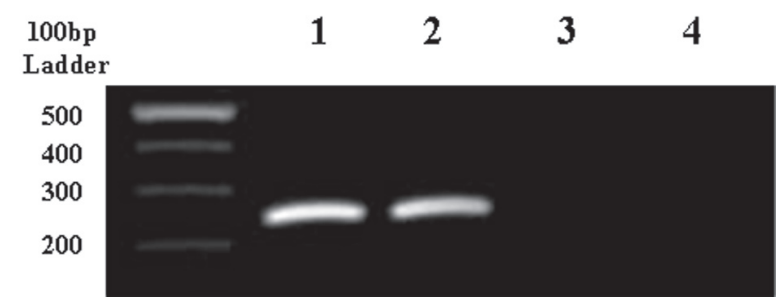

Figure 1. PDE5A expression in C2C12 cells

The expression of PDE5A was tested in proliferating cells (lane 1) and differentiated myotubes (lane 2). DNA ladder $=100 \mathrm{bp}$ (Promega). Lanes 3 and 4 are reverse transcription negative control.

To determine whether tadalafil treatment was able to influence skeletal muscle cell metabolism, C2C12 myotubes were exposed to tadalafil or vehicle for different times (30 min, $2 \mathrm{~h}$, and $24 \mathrm{~h}$ ) based on tadalafil pharmacokinetics in humans (Corbin \& Francis, 2002). The cell cultures were supplemented with $0.5 \mu \mathrm{M}$ or $1 \mu \mathrm{M}$ tadala-

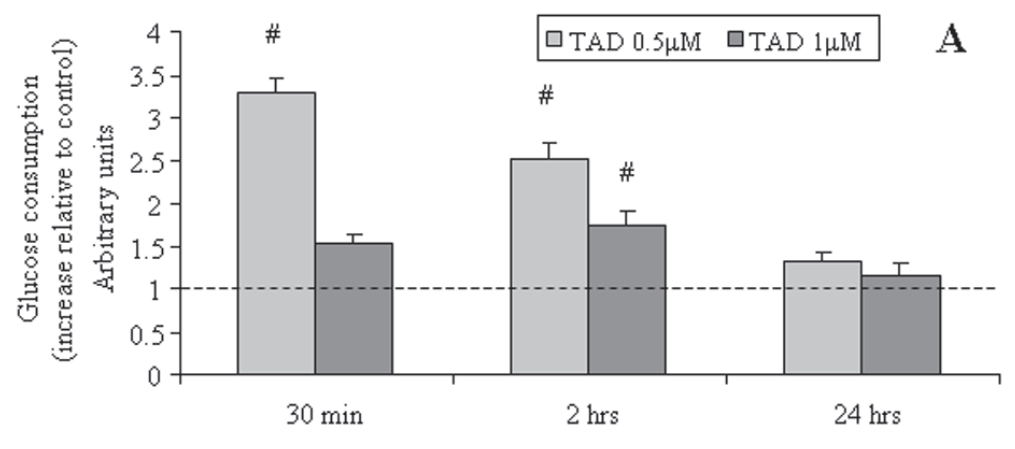

Time

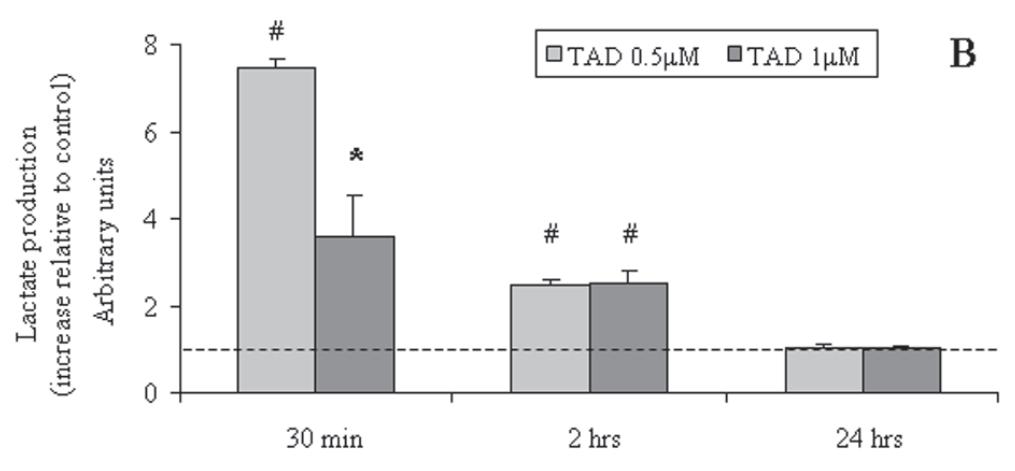

Figure 2. Glucose consumption and lactate production

C2C12 myotubes were treated with tadalafil $(0.5$ or $1 \mu \mathrm{M})$ or vehicle for $30 \mathrm{~min}, 2 \mathrm{~h}$ or $24 \mathrm{~h}$. After each treatment, culture media were collected and analyzed. Glucose (A) and lactate (B) amounts are presented as means \pm S.D. of three independent experiments, each performed in triplicate and representing increases relative to control cells. Dotted lines represent control samples normalized to $1 .{ }^{*} p<0.05, \# p<0.01$ vs. control. fil, corresponding to 10 and $20 \mathrm{mg}$ tadalafil, respectively, which is equivalent to the oral doses normally used for therapeutic treatment in vivo.

We assayed the intracellular concentration of cGMP, and as expected, we found a significant increase of the cGMP concentration with respect to the controls in all samples treated with tadalafil. The increase was more pronounced in cells treated with $1 \mu \mathrm{M}$ tadalafil (not shown). To evaluate anaerobic metabolism, we assayed glucose consumption and lactate production. Tadalafil at both concentrations induced a significant increase in glucose consumption that paralleled an augmentation of the lactate release in the culture media compared to control cells (Fig. 2).

An acute treatment with $0.5 \mu \mathrm{M}$ tadalafil for $30 \mathrm{~min}-$ utes increased glucose consumption 3.3-fold over control cells $(p<0.01)$, and at the same time, there was a significant increase in lactate release (7.5-fold over control, $p<0.01$ ) (Fig. 2).

After 2 hours of treatment, the increase in glucose consumption was maintained (2.5-fold over control cells, $p<0.01)$. The lactate production decreased after 2 hours of treatment to 2.5-fold over control cells $(p<0.05)$ (Fig. 2).

Acute treatment with $1 \mu \mathrm{M}$ tadalafil for 30 minutes increased glucose consumption 1.5-fold over control cells (not statistically significant), while the lactate release in culture media increased 3.6-fold over control cells $(p<0.05)$ (Fig. 2).

Two hours of $1 \mu \mathrm{M}$ tadalafil treatment increased glucose consumption 1.7-fold over control cells $(p<0.01)$, and the increase of the ratio of lactate production compared to control cells was also statistically significant (2.5-fold over control cells, $p<0.05$ ) (Fig. 2).

No differences were found in anaerobic metabolism after prolonged tadalafil treatment for either concentration tested with respect to control cells (Fig. 2).

Analysis of aerobic metabolism was performed by evaluating the activity of citrate synthase (CS), the key enzyme of the Krebs cycle, and 3-hydroxy acylCoA dehydrogenase (HAD), the third enzyme in the process of fatty acid $\beta$-oxidation.

Thirty minutes of treatment with $0.5 \mu \mathrm{M}$ tadalafil did not affect CS activity, although it decreased HAD activity $(12 \%$ reduction, $p<0.05)$ with respect to control cells. Both activities decreased after $2 \mathrm{~h}$ of treatment ( $42 \%$ reduction in CS activity, $p<0.01$, and $25 \%$ reduction in HAD activity, $p<0.01)$ with respect to control cells (Table 1). After $24 \mathrm{~h}$ of treatment with $0.5 \mu \mathrm{M}$ tadalafil, CS and HAD activities were comparable to those in control cells.

In contrast, exposure to $1 \mu \mathrm{M}$ tadalafil did not substantially change CS and HAD activities after $30 \mathrm{~min}$ or $2 \mathrm{~h}$ of treatment with respect to control cells. Instead, an increase of both activities, although to different extents, was observed after $24 \mathrm{~h}$ of treatment (CS ac- 
Table 1. Effect of tadalafil on C2C12 myotube aerobic metabolism

(CS) citrate synthase activity measurements were calculated by following the linear increase in absorbance at $412 \mathrm{~nm}$ using Ellman's reagent (DTNB) in an assay mixture containing $10 \mathrm{mM}$ acetyl$\mathrm{CoA}$ and $10 \mathrm{mM}$ oxaloacetate. 3-Hydroxy acylCoA dehydrogenase (HAD) activity was determined by the absorbance at $340 \mathrm{~nm}$, which represents the oxidation of $\mathrm{NADH}$ in an assay mixture containing $50 \mathrm{mM}$ triethanolamine- $\mathrm{HCl}(\mathrm{pH} 7.0), 4 \mathrm{mM}$ EDTA, $0.04 \mathrm{mM}$ $\mathrm{NADH}$ and $0.015 \mathrm{mM} \mathrm{S}$-acetoacetyl-CoA. Data are expressed as the mean \pm S.D. of three independent experiments, each performed in triplicate.

\begin{tabular}{|c|c|c|}
\hline \multicolumn{3}{|c|}{30 minutes } \\
\hline & $\mathrm{CS}^{*}$ & $\mathrm{HAD}^{\mathrm{a}}$ \\
\hline Control & $157.41 \pm 8.09$ & $40.81 \pm 3.11$ \\
\hline TAD $0.5 \mu \mathrm{M}$ & $162.70 \pm 18.46$ & $35.83 \pm 3.94^{*}$ \\
\hline TAD $1 \mu \mathrm{M}$ & $163.42 \pm 14.47$ & $36.35 \pm 3.51$ \\
\hline \multicolumn{3}{|c|}{2 hours } \\
\hline Control & $137.31 \pm 28.74$ & $36.91 \pm 3.79$ \\
\hline TAD $0.5 \mu \mathrm{M}$ & $79.83 \pm 24.98^{\#}$ & $27.59 \pm 4.46^{\#}$ \\
\hline TAD $1 \mu \mathrm{M}$ & $125.14 \pm 22.49$ & $37.97 \pm 4.98$ \\
\hline \multicolumn{3}{|c|}{24 hours } \\
\hline Control & $163.86 \pm 16.57$ & $34.67 \pm 4.68$ \\
\hline TAD $0.5 \mu \mathrm{M}$ & $151.72 \pm 14.16$ & $37.18 \pm 4.60$ \\
\hline TAD $1 \mu \mathrm{M}$ & $190.72 \pm 26.46^{*}$ & $47.70 \pm 7.23^{\#}$ \\
\hline
\end{tabular}

amU/mg protein; One unit of enzymatic activity was defined as the amount of enzyme that forms $1 \mu \mathrm{mol}$ of product per minute. ${ }^{*} p<0.05$, $\# p<0.01$ vs. control.

tivity showed a $15 \%$ increase, $p<0.05$, and HAD showed a $38 \%$ increase, $p<0.01$ ) (Table 1).

We assessed whether the effect of tadalafil on C2C12 myotube metabolism might be mediated by regulatory PDE 5 A gene expression by performing semiquantitative RT-PCR in cells treated with $1 \mu \mathrm{M}$ tadalafil or vehicle for 2 or $24 \mathrm{~h}$. Tadalafil treatment did not affect PDE5 expression (not shown), suggesting that the PDE5i exerts its effect by modulating enzymatic activity without affecting gene expression, as also reported in cultures of human penile cells (Vernet et al., 2006).

In conclusion, our data demonstrate that tadalafil exposure influences the metabolism of C2C12 skeletal muscle cells, thus indicating that cGMP signaling may play a role in the regulation of energy homeostasis in mouse skeletal muscle cells. Specifically, acute treatment with $0.5 \mu \mathrm{M}$ tadalafil improves glucose metabolism through an induction of anaerobic glycolysis with an accompanying decrease (at $2 \mathrm{~h}$ ) of aerobic metabolism, while prolonged treatment showed no effect on either metabolisms. It is of interest that an acute effect of tadalafil on glucose metabolism has been also observed in skeletal muscle of type 2 diabetic women (Jansson et al., 2010).

The quest for performance-enhancing drugs has led athletes to use tadalafil in a sport context. Our results bring to light its possible negative effects on skeletal muscle cells at low concentrations. In fact, although $0.5 \mu \mathrm{M}$ tadalafil is able to increase anaerobic metabolism, the decrease in oxidative metabolism may lead to a deficit in energy supply, therefore actually worsening rather than improving performance in sports practice.

Interestingly, acute treatment with a higher concentration of tadalafil $(1.0 \mu \mathrm{M})$ showed a moderate effect on anaerobic metabolism, although it did not affect oxidative enzyme activities. Additionally, prolonged treatment improved oxidative capacity, as displayed by the increased reliance on fat metabolism through the increase of citrate synthase and 3-OH acylCoA dehydrogenase activities. This phenomenon could be explained by the promotion of mitochondrial biogenesis induced by increased cGMP levels in myocytes (Mitsuishi et al., 2008). Moreover, it has been demonstrated in brown adipose tissue, that the modulation of protein kinase $G$ (PKG) activity, through cGMP levels, controls mitochondrial biogenesis and the induction of adipogenic markers and fat storage (Haas et al., 2009).

It can be hypothesized that chronic treatment, which causes increased fatty acid oxidation, might lead to a reduction in the use of muscle glycogen stores. Therefore, further in vivo studies are necessary to elucidate whether prolonged tadalafil supplementation with the effective dose tested may be useful for enhancing sport performance and preventing insulin resistance through the enhancement of fatty acid oxidation.

\section{Acknowledgements}

We thank Dr. C. Crescioli and Dr. M. Sottili for their helpful support.

\section{Conflict of interests}

This work presents no conflicts of interest.

\section{REFERCES}

Ayala JE, Bracy DP, Julien BM, Rottman JN, Fueger PT, Wasserman DH (2007) Chronic treatment with sildenafil improves energy balance and insulin action in high fat-fed conscious mice. Diabetes 56: 1025-1033.

Catani MV, Savini I, Duranti G, Caporossi D, Ceci R, Sabatini S, Avigliano L (2004) NF-KB and AP-1 are involved in differentiationmediated resistance to oxidative stress in skeletal muscle cell lines. Free Rad Biol Med 37: 1024-1036.

Cheng CL, Chou CH (2005) Determination of Tadalafil in small volumes of plasma by high-performance liquid chromatography with UV detection. I Chromatogr B Analyt Technol Biomed Life Sci 822: 278-284.

Corbin JD, Francis SH (2002) Pharmacology of phosphodiesterase-5 inhibitors. Int J Clin Pract 56: 453-459.

Di Luigi L, Baldari C, Sgrò P, Emerenziani GP, Gallotta MC, Bianchini S, Romanelli F, Pigozzi F, Lenzi A, Guidetti L (2008a) The type 5 phosphodiesterase inhibitor Tadalafil influences salivary cortisol, testosterone, and dehydroepiandrosterone sulphate responses to maximal exercise in healthy men. J Clin Endocrinol Metab 93: 3510-3514.

Di Luigi L, Baldari C, Pigozzi F, Emerenziani GP, Gallotta MC, Iellamo F, Ciminelli E, Sgrò P, Romanelli F, Lenzi A, Guidetti (2008b) The long-acting phosphodiesterase inhibitor Tadalafil does not influence athletes' VO2max, aerobic, and anaerobic thresholds in normoxia. Int J Sports Med 29: 110-115.

Dickinson NT, Jang EK, Haslam RJ (1997) Activation of cGMP-stimulated phosphodiesterase by nitroprusside limits cAMP accumulation in human platelets: effects on platelet aggregation. Biochem J 323: $371-377$.

Essen-Gustavsson B, Henriksson J (1984) Enzyme levels in pools of microdissected human muscle fibers of identified type. Adaptative response to exercise. Acta Physiol Scand 120: 505-515.

Flores Rodríguez J, Berzas Nevado JJ, Castañeda Peñalvo G, Mora Diez N (2004) Development of a micellar electrokinetic capillary chromatography method for the determination of three drugs employed in the erectile dysfunction therapy. I Chromatogr B Analyt Technol Biomed Life Sci 811: 231-236.

Guidetti L, Emerenziani GP, Gallotta MC, Pigozzi F, Di Luigi L, Baldari C (2008) Effect of Tadalafil on anaerobic performance indices in healthy athletes. Br J Sports Med 42: 130-133.

Haas B, Mayer P, Jennissen K, Scholz D, Diaz MB, Bloch W, Herzig S, Fässler R, Pfeifer A (2009) Protein kinase G controls brown fat cell differentiation and mitochondrial biogenesis. Sci Signal 2: ra78. 
Jansson PA, Murdolo G, Sjögren L, Nyström B, Sjöstrand M, Strindberg L, Lönnroth P (2010) Tadalafil increases muscle capillary recruitment and forearm glucose uptake in women with type 2 diabetes. Diabetologia. 53: 2205-2208.

Kulkarni SK, Patil CS (2004) Phosphodiesterase 5 enzyme and its inhibitors: update on pharmacological and therapeutical aspects. Methods Find Exp Clin Pharmacol 26: 789-799.

Liu L, Zheng S, Han P, Wei Q (2011) Phosphodiesterase-5 inhibitors for lower urinary tract symptoms secondary to benign prostatic hyperplasia: a systematic review and meta-analysis. Urology 77: 123-129.

Li L, Yee C, Beavo JA (1999) CD3- and CD28-dependent induction of PDE7 required for $T$ cell activation. Science 283: 848-851.

Loughney K, Hill TR, Florio VA, Uher L, Rosman GJ, Wolda SL, Jones BA, Howard ML, McAllister-Lucas LM, Sonnenburg WK, Francis SH, Corbin JD, Beavo JA, Ferguson K (1998) Isolation and characterization of cDNAs encoding PDE5A, a human cGMPbinding, cGMP-specific 3',5'-cyclic nucleotide phosphodiesterase. Gene 216: 139-147.

Mitsuishi M, Miyashita K, Itoh H (2008) cGMP rescues mitochondrial dysfunction induced by glucose and insulin in myocytes. Biochem Biophys Res Commun 367: 840-845.
Mounier R, Cavaliè H, Lac G, Clottes E (2007) Molecular impact of clenbuterol and isometric strenght training on rat EDL mucles. Pflugers Arch-Eur J Physiol 453: 497-507.

Omori K, Kotera J (2007) Overview of PDEs and their regulation. Circ Res 100: 309-327.

Salloum FN, Chau VQ, Hoke NN, Abbate A, Varma A, Ockaili RA, Toldo S, Kukreja RC (2009) Phosphodiesterase-5 inhibitor, Tadalafil, protects against myocardial ischemia/reperfusion through protein-kinase G-dependent generation of hydrogen sulphide. Circulation 120: S31-S36.

Soderling SH, Beavo JA (2000) Regulation of cAMP and cGMP signalling: new phosphodiesterases and new functions. Curr Opin Cell Biol 12: $174-179$

Srere PA (1969) Citrate synthase. Methods Ensymol 13: 3-11.

Vachiery JL, Huez S, Gillies H, Layton G, Hayashi N, Gao X, Naeije $R$ (2011) Safety, tolerability and pharmacokinetics of an intravenous bolus of sildenafil in patients with pulmonary arterial hypertension. Br I Clin Pharmacol 7: 289-292.

Vernet D, Magee T, Qian A, Nolazco G, Rajfer J, Gonzalez-Cadavid N (2006) Phosphodiesterase type 5 is not upregulated by tadalafil in cultures of human penile cells. J Sex Med. 3: 84-94. 